\begin{tabular}{|l|l|l||}
\hline \multicolumn{2}{|c|}{ PublisherInfo } \\
\hline \hline PublisherName & $:$ & BioMed Central \\
\hline \hline PublisherLocation & $:$ & London \\
\hline \hline PublisherImprintName & $:$ & BioMed Central \\
\hline \hline
\end{tabular}

\title{
Whole genome knockout library
}

\begin{tabular}{|l|l|l||}
\hline \multicolumn{2}{|c|}{ ArticleInfo } \\
\hline \hline ArticleID & $:$ & 4878 \\
\hline \hline ArticleDOI & $:$ & $10.1186 /$ gb-spotlight-20031111-01 \\
\hline \hline ArticleCitationID & $:$ & spotlight-20031111-01 \\
\hline \hline ArticleSequenceNumber & $:$ & 230 \\
\hline \hline ArticleCategory & $:$ & Research news \\
\hline ArticleFirstPage & $:$ & 1 \\
\hline \hline ArticleLastPage & $:$ & 3 \\
\hline \hline & & RegistrationDate : 2003-11-11 \\
ArticleHistory & $:$ & OnlineDate $\quad$ 2003-11-11 \\
\hline \hline ArticleCopyright & $:$ & BioMed Central Ltd2003 \\
\hline \hline ArticleGrants & $:$ & \\
\hline \hline ArticleContext & $:$ & 130594411 \\
\hline \hline
\end{tabular}


Cathy Holding

Email: cholding@hgmp.mrc.ac.uk

Elucidating the function of genes and intergenic sequences is the next stage in unlocking the information garnered from the completion of whole genome sequencing. Archived collections of deletion mutants in yeast and inactivating insertion mutants in Bacillus subtilis have been generated, but are time and resource demanding and require large interlaboratory collaborations. In the November 10 Proceedings of the National Academy of Sciences, Michael Jacobs and colleagues at University of Washington Genome Center report the development of a high-throughput, cost-effective method for mutagenesis in Pseudomonas aeruginosa that gives nearly 90\% disruption of open reading frames (ORFs) by the use of random transposon insertion mutagenesis. This technology yields a fully archived resource giving not only detailed information on the likely function of different genes, but also clues into essential genes - whose disruption is lethal - that may be used for therapeutic targeting. In addition, the particular construction of the transposons coupled with the use of cre-lox technology results in removal of transposon-specific sequences leaving integrated drug resistance determinants and internal epitope or affinity purification tags for selection and subsequent polypeptide analysis (Proc Natl Acad Sci USA 2003, DOI:10.1073/pnas2036282100).

Jacobs et al. constructed two transposons derived from Tn5 that generated alkaline phosphatase or $\beta$ galactosidase translational gene fusions when inserted into a target gene and that left a 63-bp insertion encoding an influenza hemagglutinin epitope and a hexahistidine metal affinity purification tag following cre-lox recombination. A random insertion library was generated for the MPAO1 isolate of $P$. aeruginosa strain PAO1 and a total of 42,240 mutant strains were archived and mapped using polymerase chain reaction. The authors observed an average success rate of $80 \%$, of which 30,100 were unique insertions in predicted ORFs. A total of 678 candidate-essential ORFs were identified and statistical and bioinformatic analysis predicted that 300 to 400 were likely to be truly essential. Validation of the library was performed using two well characterized phenotypes: loss of surface, or 'twitching,' and auxotrophy. Of 80 'confirmed twitch' ORFs, 26 were previously known, 31 were recorded as 'mobility and attachment' genes, and 23 had no known function. Of 546 disrupted ORFs resulting in auxotrophic phenotypes, 110 were defined as 'confirmed auxotrophs,' and 58 resulted from intergenic hits.

"Infections with $P$. aeruginosa are the leading cause of death in cystic fibrosis patients, and also lead to several other clinically important infections. The development of new therapies for these infections will be challenging because of the complex biology of $P$. aeruginosa. The comprehensive mutant library we have constructed will allow an accelerated genetic dissection of traits such as metabolic flexibility and inherent drug resistance that make $P$. aeruginosa such a tenacious pathogen," the authors conclude. 


\section{References}

1. Proceedings of the National Academy of Sciences USA, [http://www.pnas.org/]

2. University of Washington Genome Center, [http://www.genome.wustl.edu/]

3. The Pseudomonas aeruginosa genome: how do we use it to develop strategies for the treatment of patients with cystic fibrosis and Pseudomonas infections?

4. Respiratory virus infections in cystic fibrosis 